Dear Editor,

\section{STRESS FRACTURE OF THE TARSAL NAVICULAR}

Stress fractures of the tarsal navicular are rare with diagnosis frequently being delayed. Early diagnosis and treatment is imperative if long term disability is to be reduced. We report a patient in whom such a delay occurred.

A 27-year-old rugby player presented with a two-year history of aching pain in the right foot, present at rest but exacerbated by running. Although able to walk without a limp, any training led to severe forefoot pain. On examination there was no swelling or localised tenderness of the foot. Plain radiography of the foot and ankle failed to reveal a fracture and the patient had twice undergone a one month period of rest, without plaster cast immobilisation, followed by a further two month period of immobilisation within a plaster cast. Throughout these periods he had remained fully weight bearing.

Two years following injury an isotope bone scan was performed showing increased uptake in the tarsal navicular. Tomographic views highlighted the presence of a complete vertical fracture through the central third of the navicular. The edges were sclerotic suggesting an established nonunion. A short first metatarsal and mild metatarsus adductus were also noted.

Internal fixation with autogenous bone graft was followed by two months non-weight bearing. He made a good recovery and returned to rugby five months following surgery.

Foot pain is a common presenting symptom in many athletes. Most have a recognisable pathology demonstrated either on examination or radiographically. There are a proportion of patients, however, in whom routine investigations are negative. The use of isotope bone scanning has helped to highlight previously undiagnosed lesions.

Stress fracture of the tarsal navicular occurs in sportsmen and women who participate in running and jumping sports. Foot abnormalities, such as short first metatarsal and metatarsus adductus, may concentrate stresses on the navicular and predispose to this condition.

The fracture occurs in the sagittal plane in the central third of the bone. Approximately $50 \%$ are complete and $50 \%$ are partial, involving the proximal articular border. The central area of the navicular is relatively avascular as vessels enter the non articular surface both medially and laterally, radiating towards the centre of the bone. Fatigue fracture of this area occurs following repetitive cyclic loading.

The fracture is often missed leading to a delay in diagnosis. Pain tends to be poorly localised and there is often no swelling. Radiological diagnosis is difficult. In more than $50 \%$ of cases the fracture is not visible on plain radiography. Accurate tomography, with the navicular in the true (anatomical) anteroposterior position, is helpful, but even slight obliquity will obscure the fracture. Radioisotope bone scan is anatomically accurate but is not pathologically specific.

The treatment of stress fractures of the tarsal navicular is by immobilisation in a below-knee plaster cast. The patient should be non-weight bearing for 6 to 8 weeks. Failure to treat these fractures with non-weight bearing may result in delayed union, non-union or recurrent fractures, even if the fracture is incomplete.

Yours faithfully,

C. G. MORAN, FRCS (Ed.)

J. A. FAIRCLOUGH, FRCS*

R. C. EVANS, FRCP $†$

Dept. of General Surgery

Royal Gwent Hospital

Newport and

Depts. of Orthopaedics* and

Accident and Emergency Medicinet

Cardiff Royal Infirmary

\section{Dear Editor, \\ INSULIN-DEPENDENT DIABETES MELLITUS AND MARATHON RUNNING}

It is well known that runners who have had a myocardial infarction have completed marathons. To our knowledge there are no reports/studies referring to marathon runners with insulin dependent diabetes mellitus (IDDM). We are reporting a case of a 35-year-old male with IDDM for 17 years, who completed the Wonderful Copenhagen Marathon 1986 (WCM). He had no diabetic complications. During the run, bloodsugars were measured several times: Start $9.9 \mathrm{mmol} / \mathrm{l}, 10 \mathrm{~km} 13.3 \mathrm{mmol} / \mathrm{l}, 32 \mathrm{~km} 10.0 \mathrm{mmol} / \mathrm{l}$, $36 \mathrm{~km} 6.6 \mathrm{mmol} / \mathrm{l}$. No complaints of hypoglycaemia were reported during the run, but after finishing mild symptoms were treated by the runner eating sugar. Physical exercise has for many years been considered to be one of the basic principles in the management of diabetes. The beneficial effect of exercise is better metabolic control and less demand for insulin (Dorchy et al, 1977 and 1981). Other studies have found the same relation (Ludvigson et al, 1980). There is considerable controversy as to whether physical fitness is normal or diminished in patients with
IDDM (Poortsman et al, 1986). Several studies conclude that the degree of metabolic control is very important for the physical working capacity in IDDM (Campaigne et al, 1984; Poortsman et al, 1986). Through regular exercise diabetics may obtain more precise knowledge of their daily demand for insulin and carbohydrate requirement.

The above mentioned marathon runner had very good experience measuring his bloodsugar before and after a run. With suitable training he obtained a good degree of metabolic control. The running distance per month prior to WCM was $245 \mathrm{~km}$.

We conclude from a review of the literature and the mentioned case that it is possible for an IDDM runner with a reasonable degree of metabolic control to complete a marathon. The following advice is recommended by us for runners with IDDM:

1. Regular exercise - with a thorough knowledge of bloodsugars before and after a run.

2. If diabetic complications occur, especially cardiovascular disturbances, a physician should be consulted.

3. It is very important to carry sugar on every run (including during competition). 
4. It is not advisable to try a higher physical exercise level during competition, than during normal training.

Taking this advice seriously, the diabetic will gain much pleasure from regular running and will be able to participate in physical challenges such as marathons.

(Diabetics should not necessarily confine their exercise to running as they can participate in all forms of activity - Ed.)

Yours faithfully,

T. HARTVIG JENSEN, MD

E. DARRE, MD,

P. HOLMICH, MD

F. JAHNSEN, MD

Department of Infectious Medicine M

Rigshospitalet

Tagensvej 18

DK-2200 Copenhagen $\mathrm{N}$

Denmark
From the Wonderful Copenhagen Marathon 1986 studygroup.

\section{References}

Compaigne, B. N., Gilliam, T. B., Spencer, M. L., Lampman, R. M. and Shark, M. A., 1984 "Effects of a physical activity programme on metabolic control and cardiovascular fitness in children with insulin dependent diabetes mellitus". Diabetes Care 7: 57-62.

Dorchy, H., Jennes, M., Haumont, D., Niset, G., Loeb, H. and Poortmans, J. 1981 "Coefficient of glucose assimilation during exercise and recovery in diabetic adolescents" in Poortmans, J. and Niset, G. (Eds.): Biochemistry of exercise IV-A. Baltimore, University Park Press, pp. 273-279.

Dorchy, H., Niset, G., Oomsh, Poortmans, J. R., Baran, D. and Loeb, H., 1977 "Study of the coefficient of glucose assimilation during muscular exercise deprived of insulin". Diabete Metab. 3: 31-34.

Ludvigson, J., 1980 "Physical exercise in relation to degree of metabolic control in juvenile diabetes". Acta Paediatr.Scand (Suppl.) 283: 45-48.

Poortmans, J., Saerens, Ph., Edelman, R., Vertongen, F. and Dorchy, 1986 "Influence of the degree of metabolic control on physical fitness in type 1 diabetic adolescents". Int.Sports Med. 7: 232-235. 